\title{
SCIENCE-BASED BUDGETING FOR NATIONAL FIRE PROGRAMS
}

\author{
YU WEI ${ }^{1}$, DOUGLAS B. RIDEOUT ${ }^{1}$, ANDY G. KIRSCH ${ }^{2}$ \& NICOLE KERNOHAN ${ }^{1}$ \\ ${ }^{1}$ Colorado State University, USA \\ ${ }^{2}$ National Park Service, USA
}

\begin{abstract}
Wildland fire is an important natural disturbance that plays a key role in influencing the forest ecosystem conditions across the western US. Large and detrimental wildland fires can cause a threat to communities, infrastructures, timber production, recreation opportunities, wildlife habitat and sustainable ecosystem development efforts. Fuel treatment and wildland fire preparedness are two important strategic wildland fire planning programs for the US National Park Service (NPS). The goal of the programs is to mitigate the detrimental effects of wildland fires while promoting their beneficial effects in maintaining and restoring ecosystem conditions. NPS fire planners are tasked with efficiently allocating these fire program budgets to each of the parks. To help inform these decisions a set of production functions were applied to park specific data to describe the return on investments (ROI) at each park for the fuel treatment and preparedness programs. For each park, we calculated the first-order gradients of ROI at pre-selected investment combinations to quantify the marginal returns of investment (MROI) from both management programs. Budget allocation decisions were made by comparing MROI from both programs for all parks in a region. We iteratively allocated funding to each park and fire management programs. Climate change is a major uncertainty in wildland fire management as it may lead to longer and more severe fire seasons. We varied the ROI surfaces and ran additional simulations to study how more severe fire conditions may influence the regional budget allocation decisions. Analysing these results helps managers to identify alternative budget allocation strategies while promoting sustainable development.
\end{abstract}

Keywords: translog, production function, gradient method, fuel treatment, preparedness, climate change.

\section{INTRODUCTION}

Wildfire threatens human lives, property and natural resources [1]. Fuel accumulation, climate change and expansion of wildland urban interface have contributed to a substantial increase in federal fire expenditures during the past decade. Since fiscal year 2002, total annual fire expenditures from the US federal government have increased to an average of $\$ 3.51$ billion (US dollars) [2]. Attempts to control fire risk often rely on two interrelated programs: hazard fuel reduction and fire suppression.

Fuel reduction programs such as prescribed burning and mechanical thinning in dense forests reduce surface fire intensity, prevent crown fire, and make future fire suppression safer and more effective [3]. Initial attack (IA) focuses on containing fires within the first several hours of fire discovery [4], [5]. The success of IA often depends on the strategic investment in a fire suppression preparedness program before the start of a fire season. The decisions include determining what type and amount of suppression resources to acquire and where to base them. Climate fluctuations such as prolonged warm, dry weather conditions can contribute to more severe fire conditions [6]. We expect climate change to likely cause a growing number of large fires in the US [6]. Our research will introduce a method that can be implemented to synergize park level fuel treatment and preparedness analyses and to support the regional or national fire program budget allocation decisions before the start of each fire season. 


\section{METHODS}

We used a gradient method to support budget allocations between the fuel treatment and the wildfire preparedness programs for multiple national parks. Compared to solely maximizing the return of investment (ROI), a gradient-based approach maintains certain balances between efficiency and fairness during budget allocations. Importantly, it avoids potentially dramatic budget swings that may be disruptive to the fire management program. To implement this method, we will first adopt a set of translog production functions to estimate the ROI in each park from its fuel treatment and preparedness programs. The translog production function is more flexible than the more typical Cobb-Douglas functions as it does not restrict the values of the elasticity of substitution at any point in input space [7].

2.1 Fitting the translog production functions to calculate the ROI from the fuel treatment and the preparedness programs

We use $i$ to index each national park involved in the decision-making process. For each park $i$, at a given preparedness budget level $\left(P_{i}\right)$ and a given fuel treatment budget level $\left(F_{i}\right)$, the total ROI (denoted by $V_{i}$ ) from the investment into both fire programs follows a general form of translog production function, as demonstrated by eqn (1):

$$
\begin{aligned}
\ln V_{i}=\ln A_{i}+a_{P, i} \ln P_{i}+ & a_{F, i} \ln F_{i} \\
& +b_{P P, i} \ln ^{2} P_{i}+b_{F F, i} \ln ^{2} F_{i}+b_{F P, i} \ln F_{i} \ln P_{i} .
\end{aligned}
$$

Taking the exponential of both sides of eqn (1), we can derive eqn (2). Eqn (2) is used to directly calculate the ROI in both the fuel treatment and the preparedness programs for park $i$.

$$
V_{i}=A_{i} * P_{i}^{a_{P, i}} * F^{a_{F, i}} * e^{\ln ^{2} P_{i} * b_{P P, i}} * e^{\ln ^{2} F_{i} * b_{F F, i}} * e^{\ln P_{i} * \ln F_{i} * b_{P F, i}} .
$$

In this study, we use the empirical data from detailed fuel treatment and preparedness analyses for each park [8] to fit a set of translog production functions to capture the ROI of each park $i$. The coefficients of these production functions either reflect different elasticities from the suppression preparedness investment and the fuel treatment investment, or the elasticities from the joint impacts of the two programs. These nonlinear production equations are convex and twice differentiable within a reasonable budget range so that they can be used in the gradient method to strategically allocate budget across parks.

\subsection{Budget allocation in each park using the translog functions}

Using the translog production function an efficient budget allocation strategy was determined for increasing fire program budgets. We used the point of the current fire program budget allocation to determine the gradients of the production function and to inform the search direction. The gradient method increases the budget along the direction of the highest investment return from the current budget level (local optimal) while mitigating disruption to the current wildland fire program in each park. Disruption is mitigated because the gradient method keeps the rate of budget increasing proportional to the benefit increase in the fuels and the preparedness programs across all parks. For example, if the budget were to increase by $\$ 100$ and the preparedness program contributed 80 percent of the increase in the ROI, then the budget allocation would increase the preparedness program by $\$ 80$ and the fuels program by $\$ 20$.

To implement the gradient method for regional or national budget reallocation, we will implement the following iterative process: 
1. Calculate the marginal ROI from each additional unit of investment from the current budget level in each park and each program.

2. Increase the total regional budget by $x$ dollar (a small amount); allocate this additional investment to each fire program across all parks proportional to the marginal ROI from each program at each park; stop if the upper bound of the total possible budget amount is reached.

3. Go back to step 1 to update the marginal ROI from all parks and programs that received a portion of the $x$ dollars.

\subsection{Study the sensitivity of budget allocation by adjusting the investment elasticities}

An advantage of using the translog production function to estimate ROI is it allows us to interpret the elasticity of each type of investment relative to its ROI. This is convenient when we need to study the potential influence from uncertain factors such as the impact from climate changes. For example, with longer and warmer fire season and drier fuels, investing in the preparedness and fuel treatment programs may be more important and this could be reflected by increasing the program elasticities such as $a_{P, i}$ and $a_{F, i}$ in some of the national parks. This might especially apply to parks at higher latitudes.

\section{RESULTS}

\subsection{Fitting a set of production functions for individual parks}

Table 1 shows the fitted production function coefficients and associated significant levels for all the translog functions in five US National Parks. Within them, Glacier National Park is adjacent to the border between the US and Canada, which could potentially experience higher impact from the future climate change. These translog production functions demonstrated good fits with $R^{2}$ values ranging between $78 \%$ to $99 \%$. These production functions are listed in Table 2.

Table 1: The summary table created when translog functions were fitted based on empirical data from park level analysis from the five national parks (1) Sequoia and Kings Canyon, (2) Glacier, (3) Big Cypress, (4) Buffalo, (5) Shenandoah [8].

\begin{tabular}{|c|c|c|c|c|c|}
\hline \multicolumn{6}{|c|}{ Dependent variable: } \\
\hline \multicolumn{6}{|c|}{$\operatorname{InV}$} \\
\hline & (1) & (2) & (3) & (4) & $(5)$ \\
\hline \multirow[t]{2}{*}{ InP } & $0.045 * * *$ & $0.091 * * *$ & $0.017 * * *$ & $0.009 *$ & $0.076 * * *$ \\
\hline & $(0.001)$ & $(0.007)$ & $(0.0005)$ & $(0.005)$ & $(0.005)$ \\
\hline \multirow[t]{2}{*}{ InF } & $0.023 * * *$ & $0.024 * * *$ & $0.036 * * *$ & $0.019 * * *$ & $0.023 * * *$ \\
\hline & $(0.001)$ & $(0.006)$ & $(0.0005)$ & $(0.005)$ & $(0.005)$ \\
\hline \multirow[t]{2}{*}{ InFP } & $-0.013 * * *$ & & $-0.004 * * *$ & $-0.015 * * *$ & \\
\hline & $(0.001)$ & & $(0.001)$ & $(0.003)$ & \\
\hline \multirow[t]{2}{*}{ Constant } & $6.314 * * *$ & $5.453 * * *$ & $8.532 * * *$ & $7.218 * * *$ & $4.637 * * *$ \\
\hline & $(0.005)$ & $(0.040)$ & $(0.002)$ & $(0.016)$ & $(0.029)$ \\
\hline Observations & 55 & 55 & 55 & 55 & 55 \\
\hline$R^{2}$ & 0.970 & 0.778 & 0.993 & 0.841 & 0.810 \\
\hline Adjusted $R^{2}$ & 0.969 & 0.770 & 0.993 & 0.832 & 0.802 \\
\hline \multirow[t]{2}{*}{ Residual std. error } & 0.037 & 0.200 & 0.015 & 0.083 & 0.154 \\
\hline & $(\mathrm{df}=51)$ & $(\mathrm{df}=52)$ & $(\mathrm{df}=51)$ & $(\mathrm{df}=51)$ & $(\mathrm{df}=52)$ \\
\hline \multirow[t]{2}{*}{$F$ statistic } & $557.952 * * *$ & $91.221 * * *$ & $2576.409 * * *$ & $89.882 * * *$ & $110.608 * * *$ \\
\hline & $(\mathrm{df}=3 ; 51)$ & $(\mathrm{df}=2 ; 52)$ & $(\mathrm{df}=3 ; 51)$ & $(\mathrm{df}=3 ; 51)$ & $(\mathrm{df}=2 ; 52)$ \\
\hline
\end{tabular}


Table 2: A set of production functions to approximate the ROI (V) from different combinations of IA preparedness $(\mathrm{P})$ and hazardous fuels reduction $(\mathrm{F})$ budgets at the five selected national parks in the US.

\begin{tabular}{ll}
\hline Park name & Production function form \\
\hline Sequoia and Kings Canyon & $V=551.2495 P^{0.045} F^{0.023} e^{-0.013 \ln P \ln F}$ \\
Glacier & $V=233.4575 P^{0.091} F^{0.024}$ \\
Big Cypress & $V=5074.585 P^{0.017} F^{0.036} e^{-0.004 \ln P \ln F}$ \\
Buffalo & $V=1363.759 P^{0.009} F^{0.019} e^{-0.015 \ln P \ln F}$ \\
Shenandoah & $V=103.2342 P^{0.076} F^{0.023}$ \\
\hline
\end{tabular}

We are able to graph the ROI from the fuel treatment program and the preparedness program using the park specific analysis results [8] with the ROI estimated using the translog production functions in Table 2 (see Fig. 1).

\subsection{Regional budget allocation using translog production functions}

We conducted a regional budget analysis by using the production functions for all five national parks (Table 2) to allocate fuel treatment and IA preparedness budgets to each park and program. Preliminary study from this analysis is demonstrated in Fig. 2. We can observe the budget increasing to each park and each program as the regional budget was increased from the current 4.6 million dollars to a much higher 10 million US dollars following the gradients of the translog functions.

\subsection{Regional budget allocation under the influence of climate change}

Climate change, i.e. warmer and longer fire seasons, could potentially increase the fire intensities and the number and size of large fires; this is especially important for parks such as Glacier National Park (GLAC), which is located at a higher latitude. We would expect higher ROI from both the fuel treatment and the preparedness programs with climate change effects. In this study, we hypothetically increased the elasticities of both fuel treatment and preparedness investments in GLAC by one percent and reapplied the gradient method to allocate the fire program budget to the five national parks. Results showed that with even such a small change in the elasticities of both programs at GLAC, we can expect noticeable budget increases in both programs and especially in GLAC's fuel treatment program (Fig. 3).

\section{CONCLUSIONS AND DISCUSSIONS}

We tested a gradient based method to allocate budget between the fuel treatment programs and the IA preparedness programs across a set of five national parks in the US. This approach allocates budget increments to each park and each program proportional to their marginal advance in ROI. Budget allocation using the gradient approach is implemented according to the current program performance in each park for each fire program. This approach has the advantage of maintaining a balanced investment strategy between efficiency and the continuity of the fire programs in each park. It also represents a novel approach to synthesize park level fire programming investment analysis results to support regional or national level strategic planning efforts.

The translog production functions used in this study allow us to interpret the economic meanings of the coefficients of the production functions. It gives us the flexibility of adjusting those elasticities in an economically meaningful way to reflect the potential influences of uncertainties in climate change (or other factors) to the future park budget allocation. More research is still need to further explore the potential of using these well-defined econometric functions and implementing them in the real-world budget allocation. 

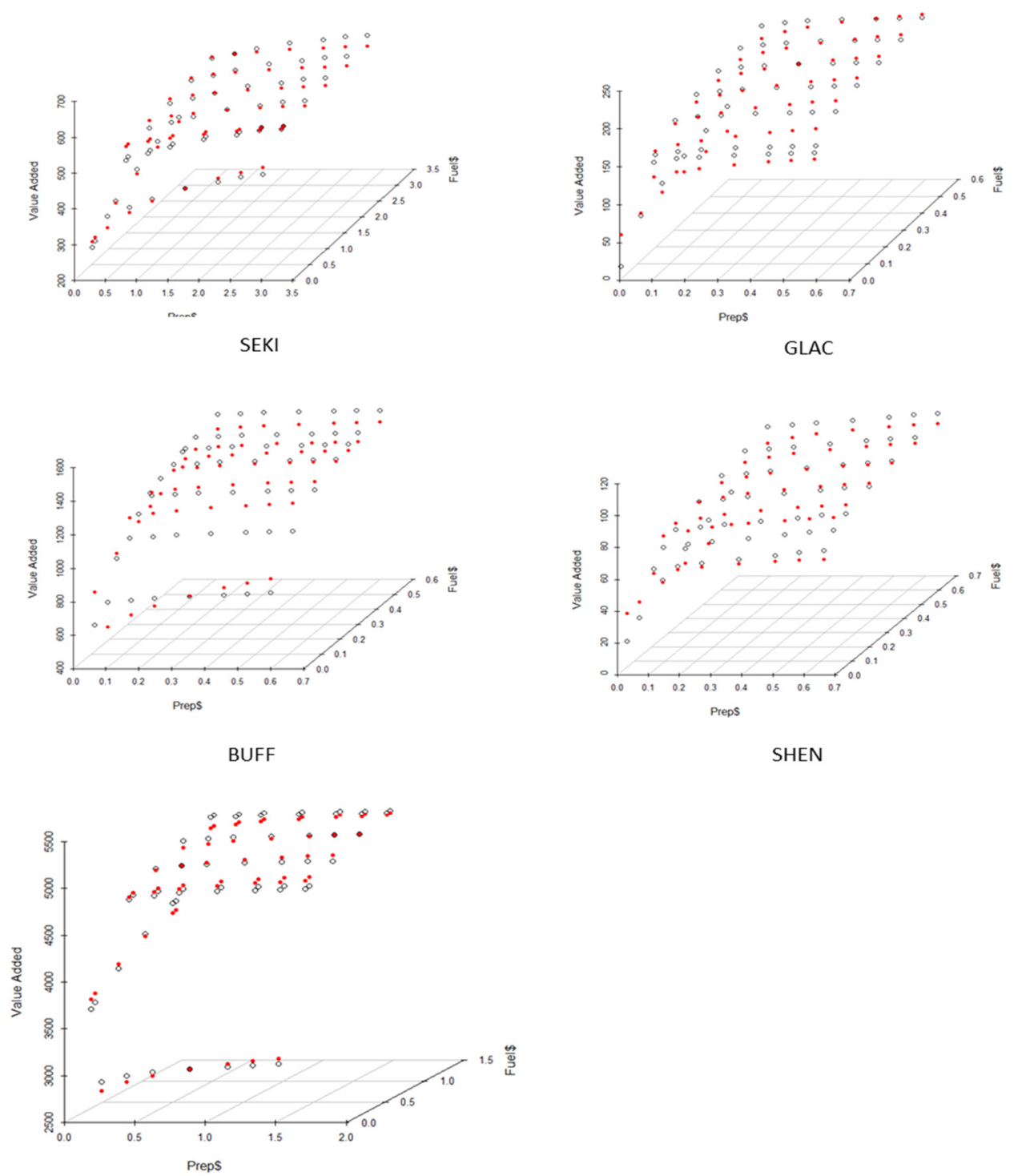

SHEN

BICY

Figure 1: Comparison of the ROI from park specific analysis results [8] (the hollow black dots) and the estimated ROI (solid red dots) from the translog production functions at the five national parks. 
112 Ecosystems and Sustainable Development XI

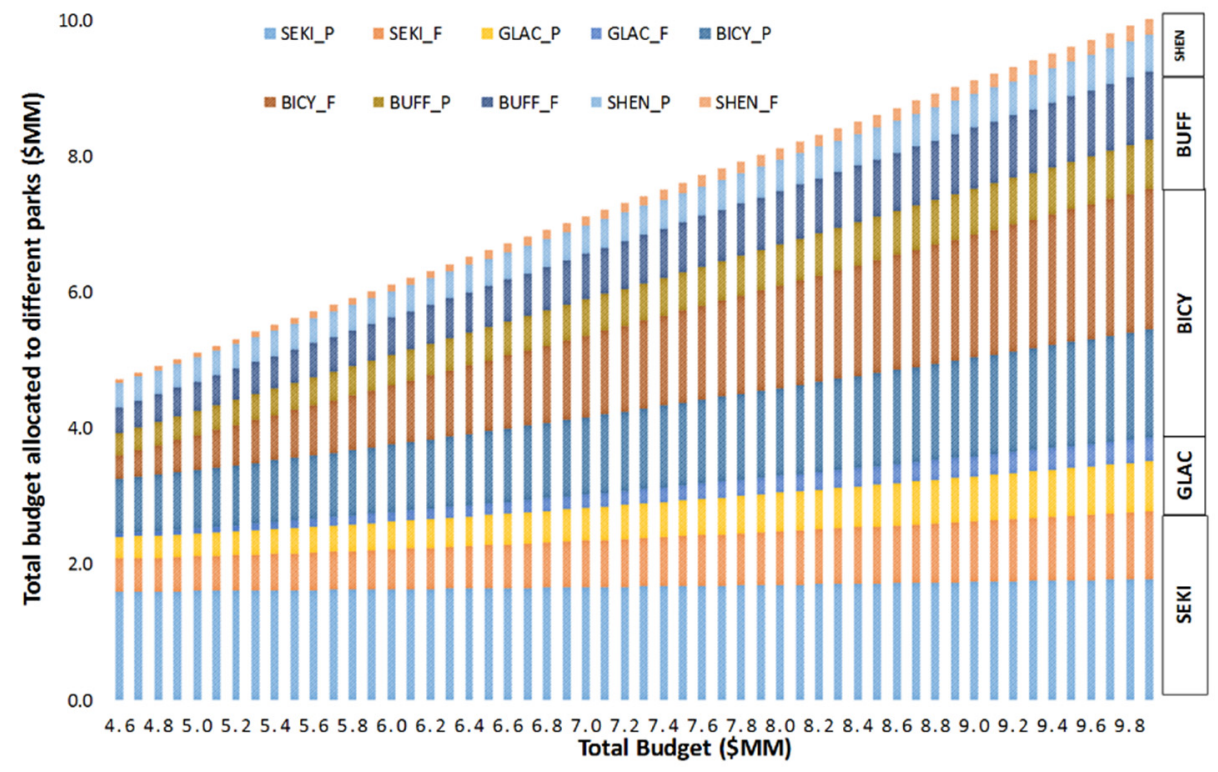

Figure 2: Budget allocation to the preparedness and fuel treatment programs for the five national parks following the gradients of the translog production functions.

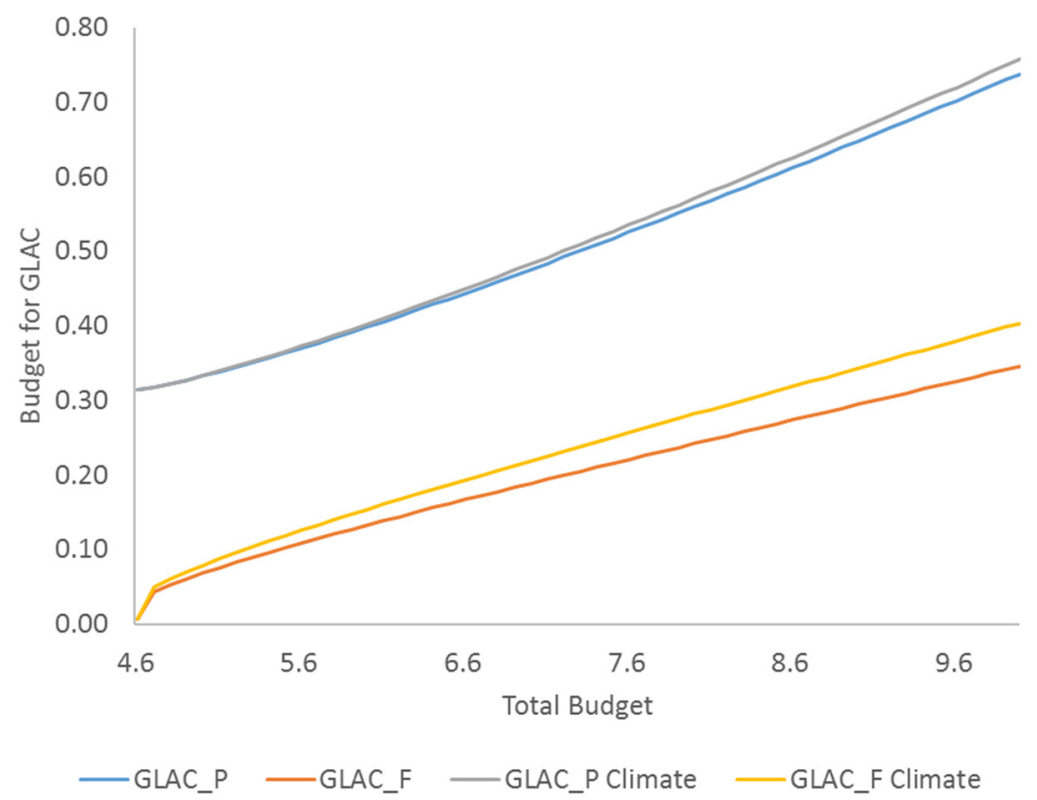

Figure 3: Comparing the budget allocation to GLAC due to the potential effects of warmer climates in the northern part of the US. 


\section{REFERENCES}

[1] King, K.J., Bradstock, R.A., Cary, G.J., Chapman, J. \& Marsden-Smedley, J.B., The relative importance of fine-scale fuel mosaics on reducing fire risk in south-west Tasmania, Australia. International Journal of Wildland Fire, 17, pp. 421-430, 2008.

[2] Headwater Economics, The rising cost of wildfire protection, 2013. Available at http://headwaterseconomics.org/wildfire/homes-risk/firecost-background/. Accessed on: 13 Jul. 2016.

[3] Loehle, C., Applying landscape principles to fire hazard reduction. Forest Ecology and Management, 198(1-3), pp. 261-267, 2004.

[4] Martell, D.L., A review of operational research studies in forest fire management. Canadian Journal of Forest Research, 12(2), pp. 119-140, 1982.

[5] Ntaimo, L., Arrubla, J.A.G., Stripling, C., Young J. \& Spencer, T., A stochastic programming standard response model for wildfire initial attack planning. Canadian Journal of Forest Research, 42, pp. 987-1001, 2012.

[6] Westerling, A.L., Hidalgo, H.G., Cayan, D.R. \& Swetnam, T.W., Warming and earlier spring increase western U.S. forest wildfire activity. Science, 313, pp. 940-943, 2006.

[7] Vittorio, C., The Translog production function some evidence from establishment data. Journal of Econometrics, 10, pp. 193-199, 1979.

[8] Rideout, D.B. Rossi, D. \& Kernohan, N., Economics of ecosystem restoration: using derived demand to promote sustainable development. Ecosystems and Sustainable Development X, eds J.L. Miralles Garcia \& C.A. Brebbia, WIT Press: Southhampton, 2015. 